\title{
Study of lignocellulosic biomass ignition properties estimation from thermogravimetric analysis
}

\author{
Blanca Castells ${ }^{\text {a, }}$, Isabel Amez ${ }^{\mathrm{a}}$, Ljiljana Medic ${ }^{\mathrm{a}}$, Nieves Fernandez-Anez ${ }^{\mathrm{b}}$, \\ Javier Garcia-Torrent ${ }^{\text {a }}$ \\ ${ }^{\text {a } U n i v e r s i d a d ~ P o l i t e ́ c n i c a ~ d e ~ M a d r i d ~ \& ~ L a b o r a t o r i o ~ O f i c i a l ~ M a d a r i a g a, ~ S p a i n ~}$ \\ ${ }^{\mathrm{b}}$ Department of Safety, Chemistry and Biomedical Laboratorio Sciences, HVL, Haugesund, Norway
}

\section{A R T I C L E I N F O}

\section{Keywords:}

Flammability

Thermal analysis

Biomass

Minimum ignition energy

\begin{abstract}
A B S T R A C T
In the last decade, the use of renewable resources has increased significantly in order to reduce the energetic dependence on fossil fuels, as they have an important contribution to the global warning and greenhouse gasses effect. Because of that, research on biofuels has been increased in the last years as its characteristics of use match those of the conventional fuel's: solid biomass can be used instead of coals, and biodiesel could replace diesel. Research on solid biomass ignition properties has been considerably developed because of the amount of industrial accidents related to the treatment and use of solid biomass (self-ignition, dust explosions, etc.). On the other hand, thermogravimetric analysis (TGA) is becoming and important characterization technique as it can be used to determine a wide spectrum of properties, such as kinetics, composition, proximate analysis, etc. This research aims to combine thermal analysis and ignition properties, by using the TGA to obtain the elemental composition of lignocellulosic biomass and compare those results to Minimum Ignition Energy (MIE) values test output, so a relation between composition and MIE can be found.

To achieve this aim, biomass samples from different origins have been used: oil palm wastes (empty fruit bunches, mesocarp fiber and palm kernel shell), agricultural wastes (straw chops) and forestry wastes (wood chips and wood powder). Also, raw materials and torrefied biomass were compared. The hemicellulose/cellulose ratio was calculated and compared to different flammability properties, finding out that the greater the ratio and the lower the onset temperature (temperature at which the pyrolysis reaction accelerates), the lower was the minimum ignition energy. From this basis it was possible to define "tendency areas" that grouped the samples whose MIE values were similar. Three tendency areas were found: high minimum ignition energy, medium minimum ignition energy, and low ignition energy.
\end{abstract}

\section{Introduction}

In the last decade, climate change had an important effect on the energetic regulations, increasing the use of renewable energies and trying to reduce the consume of fossil fuels (Chapman et al., 2018). This scenario promoted the research on new energetic sources or improving the ones already known, so they could replace the traditional energy resources. In this context, biomass has been studied so it could replace coal and its important role, as it is the only solid renewable energy (McKendry, 2002).

Even if biomass has been used for centuries, it is nowadays that several industries and facilities dedicate their activity to biomass production, storage, or handle, which means that its use has increased, and the safety conditions needed too. However, biomass flammability properties are still quite unknown and accidents keep happening such as fires, explosions and poisoning by carbon monoxide emissions (Gauthier et al., 2012; Hedlund, 2017). According to Casson Moreno and Cozzani, (2015), regarding bioenergy industry, biomass accidents are more common than biogas or bioliquid accidents. It also states the equipment involved in the accidents, and most of the fires are produced when biomass is stored in piles or bulks and the smouldering process begins, such as the fire in Plevin Recycling Plant in United Kingdom (2014) ("Plevin Hazlehead incident," 2014). On the other hand, explosions usually take place in the form of dust explosions in power plants during operations (such as material discharge, conveyor transport, etc.) that allow the dispersion of the dust into the air forming explosive

\footnotetext{
* Corresponding author. C/Alenza, 4 (despacho 422), 28003, Madrid, Spain.

E-mail address: b.castells@upm.es (B. Castells).
} 
atmospheres that may produce and explosion when ignition is produced as happened in Pinnacle Renewable Energy's wood pellet plan in Canada, 2019) ("Global News. Alberta energy plant suspends operations after explosion," 2019), or at Koda Energy combined power plant in USA, 2013 ("Star Tribune. Koda Energy invests in safer technology," 2013).

Because of this flammable nature of biomass, in the past years researches on biomass flammability properties have increased (Garcia-Torrent et al., 2016; Rupar-Gadd and Forss, 2018), trying to understand the mechanisms that take place during fires and dust explosions so that safety measures can be applied. The effect of particle size, compaction, moisture, dispersion, etc., has been widely studied (Fernandez-Anez et al., 2018; Luo et al., 2016; Saeed et al., 2017).

In order to define properly the flammable characteristics of a biomass sample, a lot of tests shall be carried out (minimum ignition temperature, self-ignition temperature, minimum ignition energy, explosion severity ...) making it a hard task. Because of this, a lot of researchers have developed methods that allow the estimation of those parameters from other tests (Fumagalli et al., 2016; Uzun et al., 2017) in order to simplify the process. Thermogravimetric analysis (TGA) has proved to be quite useful (Garcia-Torrent et al., 2016; Janković et al., 2020; Saldarriaga et al., 2015) due to the unique information that reports, the small amount of sample that requires the test and the reproducibility of the test (human error is very low).

More precisely, the parameters that influence minimum ignition energy have been widely studied not only for solid materials but also for gas mixtures (Ballal and Lefebvre, 1975; Eckhoff, 1975; Horstmann et al., 2001; Norman et al., 2013), finding out that parameters such as oxygen concentration, turbulence or particle size, among others, have a significant effect on minimum ignition energy. The amount of researches that focus on biomass minimum ignition energy is not as great as the ones that focus on coal or gas/air mixtures; but it is increasing as the use of biomass does (Abelha et al., 2016). It is also known that minimum ignition energy can provide information about ignition parameters (Frendi and Sibulkin, 1990).

On the other hand, it is necessary to have a reliable comprehension on biomass composition, as it may have an effect on the ignition properties. Biomass includes a wide range of materials, but most of them are lignocellulosic materials (Shankar et al., 2011). It means that they are composed by three main components: cellulose ( $\beta$-glucose monomers), hemicellulose (xylose, galactose, mannose, rhamnose and arabinose monomers) and lignin (substituted phenyl propane units). The composition of almost each type of lignocellulosic biomass has been previously studied, however, literature data differs from one study to another, so for the same material, different percentages of each component might be obtained (Bridgeman et al., 2008; González Martínez et al., 2019; Lewandowski, 2016). The macromolecular composition is usually obtained using an Accelerated Solvent Extractor (Jacob et al., 2013), but it is also possible to obtain an estimation of the composition through TGA, technique used by several researchers (Gaitán-Álvarez et al., 2018; Hu et al., 2016; Janković et al., 2019b).

Given this background, the present study intends to find a relation between the parameters obtained from TGA and minimum ignition energy (MIE) so a preliminary estimation can be developed. To carry out this research, different biomasses were studied, all of them lignocellulosic so a compositional relation could be studied; and subjected to thermal analysis (thermogravimetry and differential scanning calorimetry) and minimum ignition energy test. All the data obtained from the tests was carefully studied so preliminary analysis of relations between thermal parameters, composition and minimum ignition energy was developed. The purpose of this study is to provide a new tool to make an early classification of materials according to their ignition properties, by using thermal analysis, which simplifies the testing process to assess flammable characteristics.

\section{Experiments}

In this study, six different lignocellulosic biomass samples were used, from agricultural and forestry wastes. Wood powder (WP) and wood chops (WC) come from Scots pine (Pinus Sylvestris L.), straw chops (SC) are made of reed canary grass (Phalaris Arundinacea L.), and the other samples come from palm oil wastes from Malaysia (Elaeis Oleifera). The palm oil samples come from different parts of the tree: EFB sample comes from Empty Fruit Bunches, while PKS means Palm Kernel Shell, and PMF Palm Mesocarp Fiber. As torrefaction is considered an important technique to improve biomass (Van der Stelt et al., 2011), and its effects on palm wastes has been widely studied (Uemura et al., 2011), torrefied PKS and PMF have been also studied (PKS T1, PKS T2, PMF T1 and PMF T2, where $\mathrm{T} 1$ and $\mathrm{T} 2$ represents two different dry torrefaction processes, the second one more intense than the first one). The samples were chosen in order to cover a wide range of biomass types, however no sewage sludge has been used in this study, as its composition cannot be assessed trough TGA (it is not a lignocellulosic biomass).

All the samples were prepared at particle size $<1 \mathrm{~mm}$ so the tests could be performed in the same conditions for each sample. The granulometry was assessed using laser diffraction with a Mastersizer 2000 apparatus.

The samples were first characterized through proximate analysis, so moisture, ash and volatile contents were defined. Fixed carbon content was calculated from proximate analysis data on dry basis as:

Fixed carbon $=100-$ Ash $(\%)-$ Volatiles $(\%)$

\subsection{Thermogravimetric analysis (TGA)}

TGA measures the weight of the sample while it is heated from $30^{\circ} \mathrm{C}$ to $800^{\circ} \mathrm{C}$ at a constant heating rate (in this study the heating rate was $\beta=5 \mathrm{~K} / \mathrm{min}$ ). During the whole procedure, the weight is recorded so it is possible to determine the onset temperature, which is the temperature at which the reaction accelerates, and so the weight decreases significantly. TG analysis was carried out using a TG-DSC Mettler Toledo TG50 equipment.

From TGA it is also possible to obtain the apparent activation energy. Different methodologies to obtain activation energy have been developed in the last years (Hu et al., 2016; Radojević et al., 2018), however, Cumming's equation constitutes a good approximation of activation energy $\left(E_{a}\right)$ for first order kinetics and simplifies the process (Cumming, 1984).

When the first derivative of the TG curve is calculated, a second curve called DTG is obtained. This second curve provides important data such as the maximum weight loss temperature (MWL), which is the temperature at which the greatest decrease of weight takes place; but also, it is possible to obtain an estimation of the main components of lignocellulosic materials by calculating the deconvolution of the curve (Janković et al., 2019a; Perejón et al., 2011; Sronsri and Boonchom, 2018). The pseudocomponents obtained (so called because they represent an estimation instead of the precise value) will be cellulose, hemicellulose and lignin; and the area beneath those curves will represent the percentage of each component. Different deconvolution methods have been used to obtain the pseudocomponents such as Fraser-Suzuki deconvolution (Hu et al., 2016), Gaussian deconvolution (Perejón et al., 2011), DAEM method (distribution activation energy model) (Cheng et al., 2015), etc. In this study, gaussian deconvolution was used with 3 terms, resulting into the 3 pseudocomponents mentioned above. PKS samples needed 4 terms so the approach was considered good enough $\left(R^{2}\right.$ greater than 0.99$)$, and the fourth component was found to represent carbonous matter: char after test. The mathematical treatment of the data was carried out using Matlab R2016b. 


\subsection{Differential scanning calorimetry (DSC)}

DSC defines the heat exchange of the sample while heating it from $30^{\circ} \mathrm{C}$ to $550^{\circ} \mathrm{C}$ with a constant heating rate (in this study the heating rate was $\beta=20 \mathrm{~K} / \mathrm{min}$ ). The heat exchange is recorded during the whole procedure, which means that it is possible to define the exothermic and endothermic processes that take place during the heating. Three important parameters are obtained directly from the DSC curve: Initial Exothermic reaction Temperature (IET), which is the temperature at which the exothermic process begins; Change of Slope Temperature (CST), which is the temperature at which the reaction accelerates; and Final Exothermic reaction Temperature (FET), which is the temperature at which the exothermic reaction ends and is presented as a peak. DSC analysis was carried out using a TG-DSC Mettler Toledo TG-50 equipment.

From DSC data it is possible to estimate the specific heat capacity $\left(C_{p}\right)$, which is the amount of energy that one unit of mass needs to increase its temperature in one unit. The estimation is carried out following the methodology presented by Collazo et al. (2012).

\subsection{Minimum ignition energy (MIE)}

MIE is the minimum ignition required to ignite the sample dispersed into air forming a cloud using a high voltage capacitor discharge. The procedure of the test is carried out according to the standard EN ISO/IEC 80079-20-2:2016 (European committee for standardization CEN-CENELEC, 2016), and the energy is calculated as follows:

$M I E=\frac{1}{2} \cdot C \cdot U^{2}$

Where $C$ is the capacity of discharge expressed in Farads, and $U$ is the applied voltage expressed in Volts. The test was carried out using a MIKE 3 apparatus that incorporates a Hartmann tube.

\section{Results and discussion}

The results from the proximate analysis and granulometry can be shown in Table 1. The moisture content presents the lowest values in the torrefied samples, as torrefaction reduces the hygroscopicity of the biomasses. The woody samples have the lowest ash content but the highest volatile percentage which means that an important amount of the sample has weak bonds and the onset temperature will be greater as the acceleration will take place after volatilizing most of this matter.

\subsection{Thermal analysis (TGA and DSC)}

In most of the biomass samples the IET represents the very beginning of the reaction, afterwards onset temperature indicates the moment of which it begins to accelerate, the CST would be greater than the onset temperature as indicates when the rapid exothermic reaction begins and it will be close to the MWL temperature, as when the process accelerates, the weight loss increases. Finally, the FET will define the end of the

Table 1

Proximate analysis.

\begin{tabular}{lllll}
\hline Sample & Moisture & Ash d.b. & Volatile d.b. & Fixed Carbon d.b. \\
\hline PKS & $7.0 \%$ & $9.5 \%$ & $66.8 \%$ & $23.7 \%$ \\
PKS T1 & $0.5 \%$ & $5.4 \%$ & $72.1 \%$ & $22.5 \%$ \\
PKS T2 & $0.9 \%$ & $4.4 \%$ & $73.0 \%$ & $22.6 \%$ \\
EFB & $6.5 \%$ & $2.9 \%$ & $72.7 \%$ & $24.4 \%$ \\
PMF & $8.8 \%$ & $5.8 \%$ & $62.7 \%$ & $31.5 \%$ \\
PMF T1 & $1.4 \%$ & $6.3 \%$ & $73.8 \%$ & $20.0 \%$ \\
PMF T2 & $1.1 \%$ & $6.6 \%$ & $72.6 \%$ & $20.8 \%$ \\
WC & $6.2 \%$ & $0.2 \%$ & $85.6 \%$ & $14.3 \%$ \\
WP & $5.8 \%$ & $0.2 \%$ & $84.1 \%$ & $15.8 \%$ \\
SC & $5.1 \%$ & $6.4 \%$ & $76.5 \%$ & $17.1 \%$ \\
\hline
\end{tabular}

exothermic reaction, and from this point so on the sample will be mostly char. For each sample, those temperatures are shown in Table 2, also adding the apparent activation energy and the specific heat capacity.

Kernel shell samples (PKS) present the greatest IET temperatures, as they present strong chemical bonds (Alengaram et al., 2010) and so the exothermic reaction requires greater temperatures to start, even more after torrefaction process. Besides PKS, the remaining samples exothermic reaction begins between $80^{\circ} \mathrm{C}$ and $100^{\circ} \mathrm{C}$ and present the exothermic peak (FET) between $510^{\circ} \mathrm{C}$ and $550^{\circ} \mathrm{C}$, where the exothermic reaction ends. At FET temperatures, the mass recorded during the TG analysis was close to the char content, as the reaction was finished.

Torrefied samples have lower $C_{p}$ values, as torrefaction improves the energetic parameters of the biomasses besides PMF T2, whose behaviour is not as expected, and will be explained when discussing pseudocomponents results. On the other hand, the activation energy has an effect on the onset temperature, as the $E_{a}$ is the minimum energy required for a system to start a process, the highest energies correspond to the highest onset temperatures as the system requires more heat to start the process. However, there is no significant relation between activation energy and CST. This fact can be due to the effect of the volatile content of the sample. In the first stage of the process, the light volatile matter will be released accelerating the combustion and defining onset temperature.

Table 3 shows the pseudocomponents percentage for each sample, obtained by Gaussian deconvolution. In addition, the table shows the obtained $R^{2}$, which represents the quality of the fitted model; and the char percentage, which is the matter percentage that remained after the TG analysis. As it was explained above, PKS samples needed 4 terms deconvolution due to the great char amount of the samples. A great char content implies that the sample contains non-combustible matter that needs to be represented, in this case, through the carbonous matter of the sample that was estimated with the fourth component $(25.14 \%$ for PKS, 23.27\% for PKS T1 and $20.08 \%$ for PKS T2).

The deconvolution of WP did not reach the $0.99 R^{2}$ expected, however the results of each component are consistent if compared to bibliographic data for Scots pine (Zborowska et al., 2018), so the obtained results are considered accurate enough. PMF and PKS samples show an increase of lignin after torrefaction process due to the decomposition of hemicellulose and degradation of cellulose, which can also be noticed in the results. However, PMF T2 behaves in a completely different way, reducing its lignin content and increasing the cellulose, which might be related to the thermal behaviour during the TGA. TGA analysis was carried out twice for PMF T2, and its irregular behaviour remained during both tests. Fig. 1 shows the curves from the thermal analysis for PMF, PMF T1 and PMF T2, where it is possible to see that PMF combustion decreases around $300^{\circ} \mathrm{C}$ and so the slope increases. Torrefaction should correct this behaviour and so it happens when testing PMF T1, however, PMF T2 shows this "slow combustion" phenomena again, complicating the estimation of pseudocomponents through TGA.

Table 2

Thermal analysis: TG and DSC.

\begin{tabular}{llllllll}
\hline Sample & $\begin{array}{l}\text { IET } \\
\left({ }^{\circ} \mathbf{C}\right)\end{array}$ & $\begin{array}{l}\text { Onset } \\
\left({ }^{\circ} \mathbf{C}\right)\end{array}$ & $\begin{array}{l}\text { CST } \\
\left({ }^{\circ} \mathbf{C}\right)\end{array}$ & $\begin{array}{l}\text { MWL } \\
\left({ }^{\circ} \mathbf{C}\right)\end{array}$ & $\begin{array}{l}\text { FET } \\
\left({ }^{\circ} \mathbf{C}\right)\end{array}$ & $\begin{array}{l}\mathbf{E}_{\mathbf{a}} \\
(\mathbf{k J} / \\
\mathbf{m o l})\end{array}$ & $\begin{array}{l}\mathrm{C}_{\mathbf{p}}(\mathbf{J} / \\
\mathbf{k g} \cdot \mathbf{K})\end{array}$ \\
\hline PKS & 105.9 & 218.4 & 242.5 & 344.6 & 535.2 & 67.7 & 2589.6 \\
PKS T1 & 220.0 & 250.0 & 334.0 & 350.0 & 545.0 & 67.9 & 1794.7 \\
PKS T2 & 221.0 & 251.2 & 333.0 & 350.0 & 545.0 & 68.3 & 762.3 \\
EFB & 72.0 & 236.8 & 317.0 & 315.4 & 513.0 & 66.0 & 1235.4 \\
PMF & 80.3 & 222.7 & 289.5 & 310.0 & 527.5 & 65.5 & 2492.9 \\
PMF T1 & 70.8 & 244.2 & 300.6 & 339.3 & 526.9 & 67.1 & 349.2 \\
PMF T2 & 88.9 & 241.2 & 359.2 & 304.6 & 543.2 & 66.1 & 1388.0 \\
WC & 94.0 & 271.1 & 376.0 & 339.4 & 529.0 & 70.6 & 1955.1 \\
WP & 85.0 & 263.6 & 377.0 & 320.6 & 530.0 & 68.6 & 622.3 \\
SC & 94.0 & 239.3 & 375.0 & 328.7 & 530.0 & 67.4 & 578.9 \\
\hline
\end{tabular}


Table 3

Pseudocomponents from Gaussian deconvolution and char percentage.

\begin{tabular}{llllll}
\hline Sample & $\begin{array}{l}\text { Cellulose } \\
(\%)\end{array}$ & $\begin{array}{l}\text { Hemicellulose } \\
(\%)\end{array}$ & $\begin{array}{l}\text { Lignin } \\
(\%)\end{array}$ & $\mathbf{R}^{\mathbf{2}}$ & $\begin{array}{l}\text { Char } \\
(\%)\end{array}$ \\
\hline PKS & 13.1 & 8.4 & 13.1 & 0.9986 & 30.3 \\
PKS T1 & 17.8 & 10.9 & 15.4 & 0.9978 & 31.9 \\
PKS T2 & 9.2 & 11.0 & 22.8 & 0.9973 & 35.9 \\
EFB & 43.1 & 20.8 & 8.0 & 0.9995 & 19.0 \\
PMF & 45.6 & 29.2 & 14.5 & 0.9902 & 1.7 \\
PMF T1 & 24.1 & 27.7 & 18.4 & 0.9946 & 27.7 \\
PMF T2 & 52.7 & 39.0 & 4.0 & 0.9942 & 3.0 \\
WC & 39.6 & 23.4 & 16.2 & 0.9924 & 14.2 \\
WP & 45.2 & 21.5 & 23.7 & 0.9833 & 2.9 \\
SC & 48.0 & 25.2 & 15.3 & 0.9953 & 4.2 \\
\hline
\end{tabular}

The figure also presents the main stages of the TG analysis. Between initial temperature and $105^{\circ} \mathrm{C}$ there is a moisture release stage, and the sample is dried. After that, the sample starts heating and between $200^{\circ} \mathrm{C}$ and $300^{\circ} \mathrm{C}$ the acceleration of the process takes place. The observed peaks in the DTG curve represent the decomposition of light and heavy volatiles. Cellulose and part of the hemicellulose are devolatilized during light volatile decomposition, while the remaining hemicellulose mostly decomposes during the heavy volatile decomposition and lignin decomposes over a wider range (between $200^{\circ} \mathrm{C}$ and $500^{\circ} \mathrm{C}$ ) (Dorez et al., 2014).

\subsection{Minimum ignition energy}

The results obtained from the MIE test are shown in Table 4. As occurred when assessing the specific heat capacity, torrefied samples present lower MIE values than their original sample. The woody samples have the same MIE value, as both are the same species and their thermal characteristics were very similar. From those results, three different groups can be made: samples with high minimum energy (PKS, EFB, WC and WP), samples with medium-low minimum energy (PKS T1, PMF and SC) and samples with low minimum energy (PKS T2, PMF T1 and PMF T2). The previous tests showed an "erratic" behaviour of PMF T2 which also manifests in MIE results as MIE increases from PMF T1 to PMF T2. However, this fact can also be explained because of its particle size distribution, which can be seen also in Table 4, and shows an increase of particle size if compared to PMF T1. The fact that minimum ignition energy decreases after torrefaction has been contrasted in previous literature, however the previous studies show discordance when approaching the relation between explosivity and torrefaction (Boskovic et al., 2015; Szamosi et al., 2017; Thrän et al., 2016); which could be explained by the feedstock type. Indeed, torrefaction may present different effects depending on the chemical and physical structure of the sample. If particle size is considered, kernel shell samples increase granulometry after torrefaction, probably because the smaller particles volatilize as torrefaction affects to the available surface and might volatilize small particles so the mostly the great particles remain, increasing granulometry. On the other hand, when mesocarp fibre is tested, granulometry decreases after torrefaction, which could be due to the bonds break in the sample structure, so the particles are weaker and break easily into smaller particles.

Lignin is a polymer that binds the fibres of the cells and vessels acting as a cementing agent, which means that this molecule is stronger than cellulose and hemicellulose. According to that, the minimum ignition will be related to the percentage of each component, as the samples with higher hemicellulose will require less energy to break the chemical bonds in the combustion. However, from the contents obtained above, no relation was found between MIE and pseudocomponents content, so the ratios hemicellulose/cellulose, hemicellulose/lignin and cellulose/ lignin were calculated in order to find out if the proportion between components may produce an effect on the minimum ignition energy. From this data, it was inferred that the lignin content does not affect the MIE as much as hemicellulose and cellulose. Fig. 2 plots the hemicellulose/cellulose ratio versus some of the flammability parameters explained above: fixed carbon content, specific heat capacity, apparent activation energy and onset temperature.

The samples with the lowest minimum ignition energies are always located in the lower right quadrant of the plots, as their hemicellulose/ cellulose ratios are higher than the ratios of the other samples. More precisely, those samples whose minimum energy was lower than $100 \mathrm{~mJ}$ presented ratios greater than 0.7: PMF T2 has a ratio of 0.74 (and the highest MIE from low MIE group) and PMF T1 and PKS T2 have ratios over 1 (1.15 and 1.2 respectively).

The samples with high MIE seem to have lower ratios, however PKS's (whose MIE is $840 \mathrm{~mJ}$ ) ratio is 0.64 and behaves more similar to the medium MIE group than to the high MIE group. The fixed carbon content varies in a short range for the low MIE group (Fig. 2 a), however for the rest of the groups present an important dispersion. Same fact could be stated for the apparent activation energy (Fig. 2 c), but it could be due

Table 4

MIE and particle size distribution.

\begin{tabular}{lllll}
\hline Sample & MIE $(\mathbf{m J})$ & $\mathbf{d 1 0}$ & $\mathbf{d 5 0}$ & $\mathbf{d 9 0}$ \\
\hline PKS & 840 & 4.2 & 189.7 & 1021.6 \\
PKS T1 & 200 & 11.6 & 234.0 & 745.0 \\
PKS T2 & 55 & 272.4 & 730.9 & 1350.8 \\
EFB & 610 & 30.0 & 146.5 & 414.7 \\
PMF & 220 & 41.9 & 367.9 & 1354.2 \\
PMF T1 & 55 & 7.9 & 125.4 & 337.9 \\
PMF T2 & 79 & 32.5 & 103.2 & 1421.8 \\
WC & 610 & 152.7 & 619.4 & 1307.8 \\
WP & 610 & 171.1 & 613.4 & 1295.2 \\
SC & 220 & 125.9 & 457.6 & 1227.5 \\
\hline
\end{tabular}

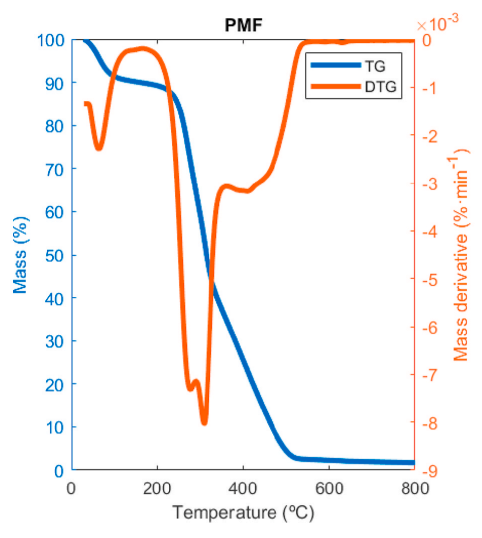

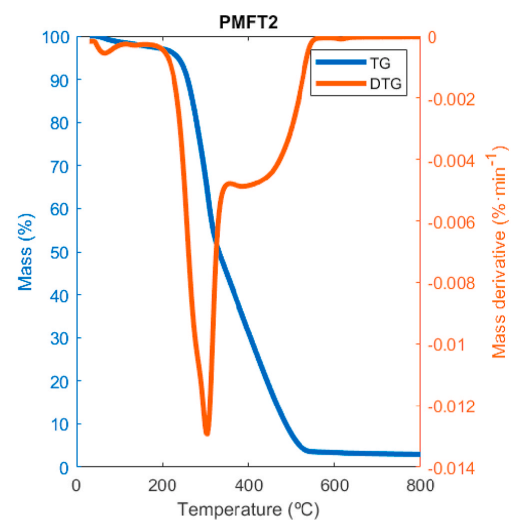

Fig. 1. TGA of palm mesocarp fiber samples. 


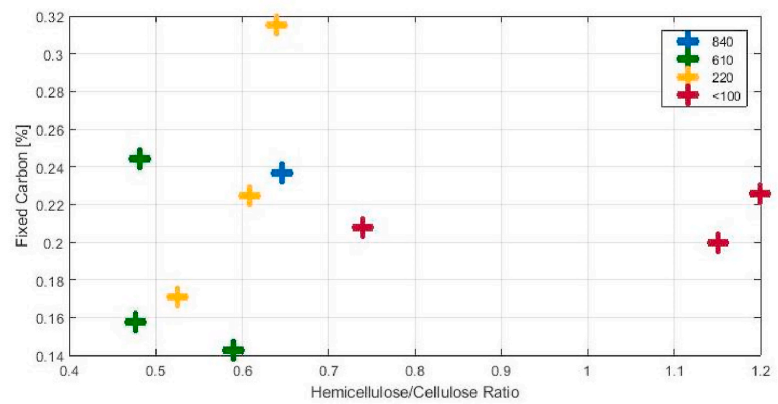

a)

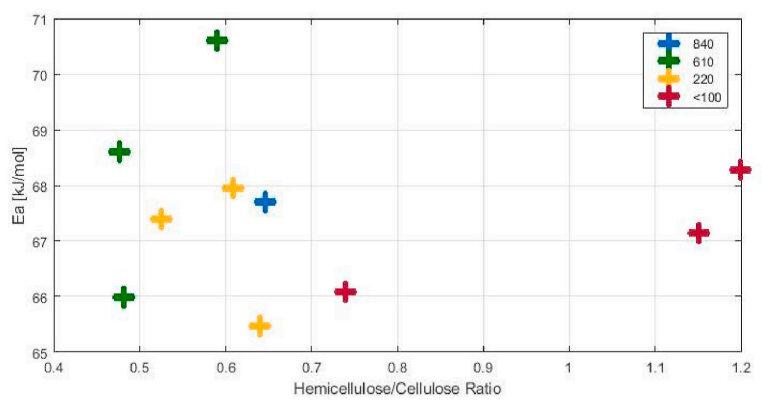

c)

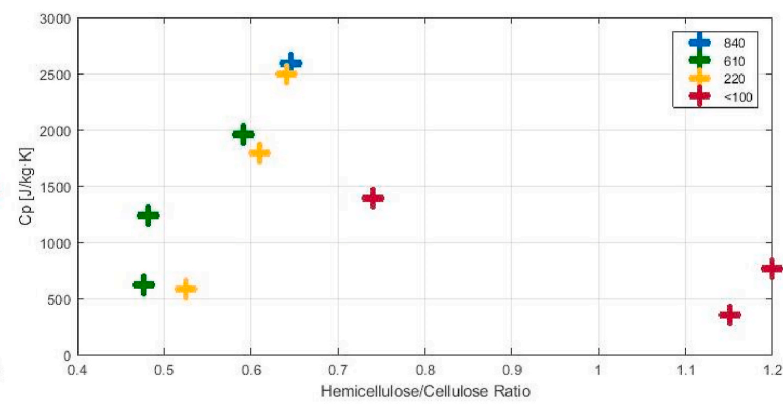

b)

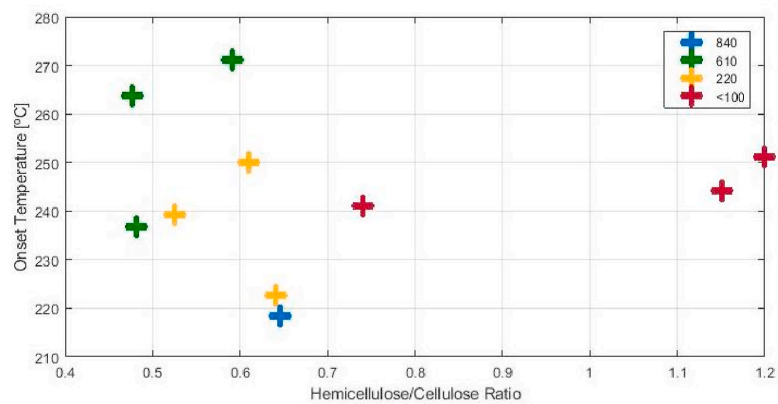

d)

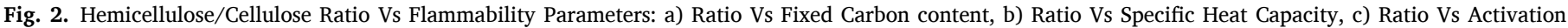
Energy, d) Ratio Vs Onset Temperature.

to the fact that the activation energy was calculated as a first order kinetics and the values are an approximation. As Ea is a parameter that have been proved useful to estimate self-ignition tendency (Garcia-Torrent et al., 2016), it can be expected that it has an effect on the minimum ignition energy, so further studies would be required in order to define the kinetics best fit in each sample, and so more accurate values would be obtained. Regarding the specific heat capacity (Fig. 2 b), there is no significant relation to MIE, as the lowest $\mathrm{Cp}$ values corresponds to samples whose MIE is $55 \mathrm{~mJ}, 220 \mathrm{~mJ}$ and $610 \mathrm{~mJ}$.
The most significant plot is Fig. $2 \mathrm{~d}$, in which the ratio is plotted versus the onset temperature. It seems to be a tendency that samples with great onset temperatures, and low hemicellulose/cellulose ratios have higher MIEs than the samples that locate in the opposite part of the plot. Fig. 3 shows the three MIE groups (high, medium, and low), and establish around them "tendency areas". From this plot it is possible to make a preliminary classification of samples according to these tendency areas.

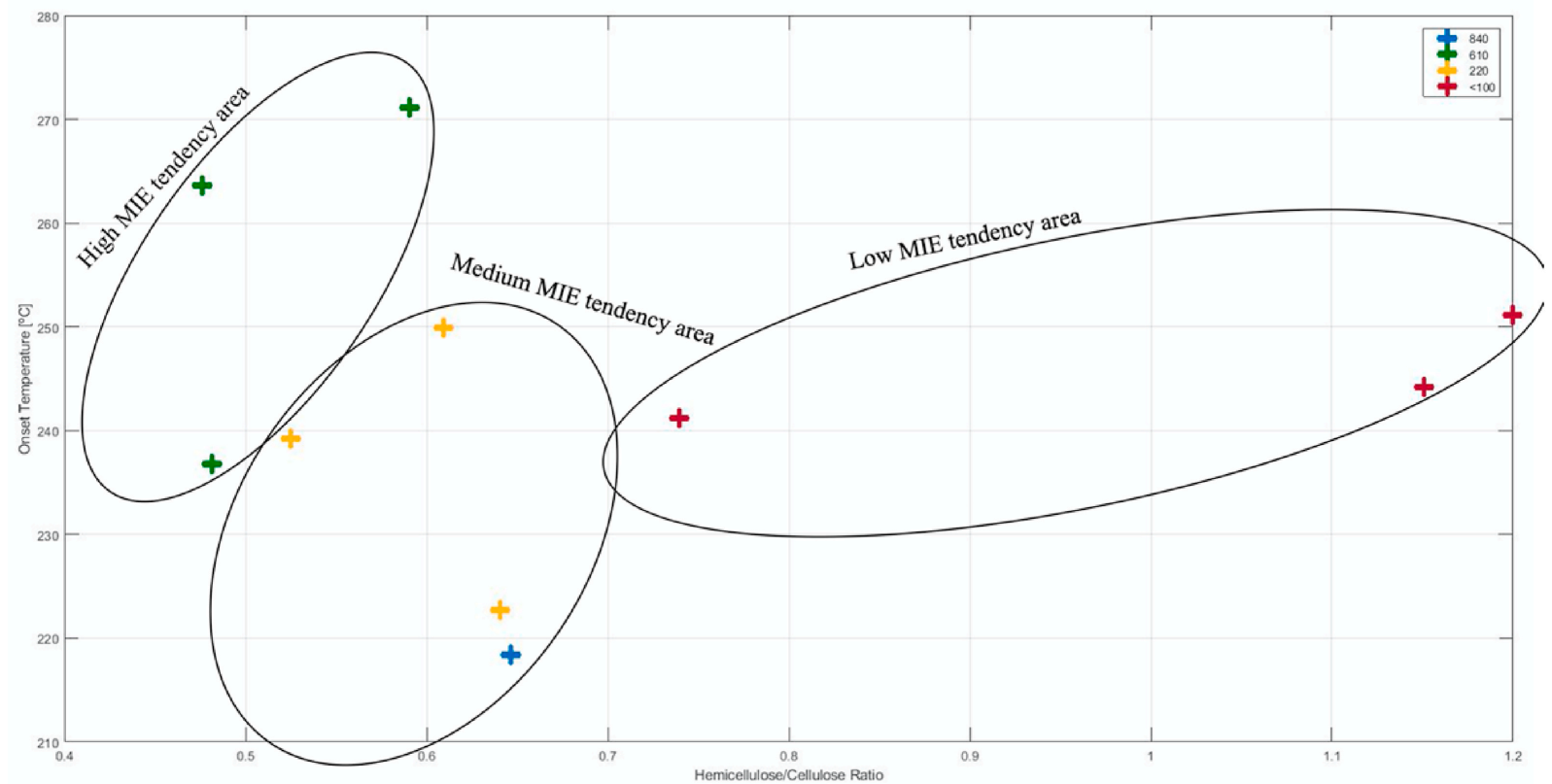

Fig. 3. MIE tendency areas. 


\section{Conclusions}

The first conclusion that can be obtained from the tests result is that torrefaction treatment may have an important effect on the flammability properties of the samples depending on the feedstock. It has been proved that palm wastes torrefied samples have lower MIE values than the original samples, but also the specific heat capacity was reduced in those samples. It means that torrefied palm oil wastes might require special safety measures as their ignition does not need great amounts of energy.

The lignin content does not have a significant effect on the flammability characteristics of the samples however, the proportion between hemicellulose and cellulose appears to group samples with similar MIE. More precisely, when evaluating the hemicellulose/cellulose ratio and the onset temperature there is a tendency to increase minimum ignition energy as the ratio decreases and the onset temperature increases. It means that if the ratio is plotted versus onset temperature, the samples that locates in the upper left part of the plot will have greater minimum ignition energy than those that locate in the lower right part.

PMF T2 sample behaves in an unexpected way, however the data evaluated in this study is not enough to state that the sample constitutes a deviation or not. It would be necessary to test similar samples (biomasses made from fibres), so a proper tendency is defined. Further studies will focus on adding samples and studying their properties so the estimation can be fully reliable, and it will be possible to define classification zones instead of tendency areas.

\section{Author statement}

Blanca Castells: Conceptualization, Data curation, Formal analysis, Investigation, Methodology, Resources, Software, Roles/Writing - original draft. Isabel Amez: Formal analysis, Investigation, Resources, Validation, Visualization, Roles/Writing - original draft. Ljiljana Medic: Project administration, Validation, Visualization, Writing - review \& editing. Nieves Fernandez-Anez: Formal analysis, Methodology, Validation, Visualization, Writing - review \& editing. Javier Garcia-Torrent: Project administration, Supervision, Writing - review \& editing.

\section{Declaration of competing interest}

The authors declare that they have no known competing financial interests or personal relationships that could have appeared to influence the work reported in this paper.

\section{References}

Abelha, P., Carbo, M., Cieplik, M., 2016. Explosivity properties of dusts from torrefied biomass pellets. Chem. Eng. Trans. 48, 403-408. https://doi.org/10.3303/ CET1648068.

Alengaram, U.J., Mahmud, H., Jumaat, M.Z., 2010. Comparison of mechanical and bond properties of oil palm kernel shell concrete with normal weight concrete. Int. J. Phys. Sci. 5, 1231-1239.

Ballal, D.R., Lefebvre, A.H., 1975. The influence of flow parameters on minimum ignition energy and quenching distance. Symp. Combust. 15, 1473-1481. https://doi.org/ 10.1016/S0082-0784(75)80405-X.

Boskovic, A., Basu, P., Amyotte, P.R., 2015. An exploratory study of explosion potential of dust from torrefied biomass. Can. J. Chem. Eng. 93, 658-663. https://doi.org/ 10.1002/cjce. 22153 .

Bridgeman, T.G., Jones, J.M., Shield, I., Williams, P.T., 2008. Torrefaction of reed canary grass, wheat straw and willow to enhance solid fuel qualities and combustion properties. Fuel 87, 844-856. https://doi.org/10.1016/j.fuel.2007.05.041.

Casson Moreno, V., Cozzani, V., 2015. Major accident hazard in bioenergy production. J. Loss Prev. Process. Ind. 35, 135-144. https://doi.org/10.1016/j.jlp.2015.04.004.

Chapman, A.J., McLellan, B.C., Tezuka, T., 2018. Prioritizing mitigation efforts considering co-benefits, equity and energy justice: fossil fuel to renewable energy transition pathways. Appl. Energy 219, 187-198. https://doi.org/10.1016/j. apenergy.2018.03.054.

Cheng, Z., Wu, W., Ji, P., Zhou, X., Liu, R., Cai, J., 2015. Applicability of Fraser-Suzuki function in kinetic analysis of DAEM processes and lignocellulosic biomass pyrolysis processes. J. Therm. Anal. Calorim. 119, 1429-1438. https://doi.org/10.1007/ s10973-014-4215-3.
Collazo, J., Pazó, J.A., Granada, E., Saavedra, Á., Eguía, P., 2012. Determination of the specific heat of biomass materials and the combustion energy of coke by DSC analysis. Energy 45, 746-752. https://doi.org/10.1016/j.energy.2012.07.018.

Cumming, J.W., 1984. Reactivity assessment of coals via a weighted mean activation energy. Fuel 63, 1436-1440. https://doi.org/10.1016/0016-2361(84)90353-3.

Dorez, G., Ferry, L., Sonnier, R., Taguet, A., Lopez-Cuesta, J.M., 2014. Effect of cellulose, hemicellulose and lignin contents on pyrolysis and combustion of natural fibers. J. Anal. Appl. Pyrolysis 107, 323-331. https://doi.org/10.1016/j.jaap.2014.03.017.

Eckhoff, R.K., 1975. Towards absolute minimum ignition energies for dust clouds? Combust. Flame 24, 53-64. https://doi.org/10.1016/0010-2180(75)90128-5.

European committee for standardization CEN-CENELEC, 2016. ISO/IEC 80079-20-2 2016 Explosive Atmospheres - Part 20-2: Material Characteristics - Combustible Dusts Test Methods.

Fernandez-Anez, N., Slatter, D.J.F., Saeed, M.A., Phylaktou, H.N., Andrews, G.E., GarciaTorrent, J., 2018. Ignition sensitivity of solid fuel mixtures. Fuel 223, 451-461. https://doi.org/10.1016/j.fuel.2018.02.106.

Frendi, A., Sibulkin, M., 1990. Dependence of minimum ignition energy on ignition parameters. Combust. Sci. Technol. 73, 395-413. https://doi.org/10.1080/ 00102209008951659.

Fumagalli, A., Derudi, M., Rota, R., Copelli, S., 2016. Estimation of the deflagration index KSt for dust explosions: a review. J. Loss Prev. Process. Ind. 44, 311-322. https:// doi.org/10.1016/j.jlp.2016.09.011.

Gaitán-Álvarez, J., Moya, R., Puente-Urbina, A., Rodriguez-Zúñiga, A., 2018. Thermogravimetric, devolatilization rate, and differential scanning calorimetry analyses of biomass of tropical plantation species of Costa Rica torrefied at different temperatures and times. Energies 11. https://doi.org/10.3390/en11040696.

Garcia-Torrent, J., Ramírez, Á., Fernandez-Anez, N., Medic, L., Tascón, A., 2016. Influence of the composition of solid biomass in the flammability and susceptibility to spontaneous combustion. Fuel 184, 503-511. https://doi.org/10.1016/j. fuel.2016.07.045.

Gauthier, S., Grass, H., Lory, M., Krämer, T., Thali, M., Bartsch, C., 2012. Lethal carbon monoxide poisoning in wood pellet storerooms-two cases and a review of the literature. Ann. Occup. Hyg. 56, 755-763. https://doi.org/10.1093/annhyg/ mes047.

Global News, 2019. Alberta Energy Plant Suspends Operations after Explosion [WWW Document]. Glob. News, 12.19.19. https://globalnews.ca/news/4953314/pi nnacle-entwistle-energy-plant-explosion-injuries/.

González Martínez, M., Ohra-aho, T., Tamminen, T., da Silva Perez, D., Campargue, M., Dupont, C., 2019. Detailed structural elucidation of different lignocellulosic biomass types using optimized temperature and time profiles in fractionated Py-GC/MS. J. Anal. Appl. Pyrolysis 140, 112-124. https://doi.org/10.1016/j.jaap.2019.02.011.

Hedlund, F.H., 2017. Biomass accident investigations - missed opportunities for learning and accident prevention. Eur. Biomass Conf. Exhib. Proc. 2017, 1804-1814. https:// doi.org/10.5071/25thEUBCE2017-4AV.2.45.

Horstmann, T., Leuckel, W., Maurer, B., Maas, U., 2001. Influence of turbulent flow conditions on the ignition of flammable gas/air-mixtures. Process Saf. Prog. 20, 215-224. https://doi.org/10.1002/prs.680200311.

Hu, M., Chen, Z., Wang, S., Guo, D., Ma, C., Zhou, Y., Chen, J., Laghari, M., Fazal, S. Xiao, B., Zhang, B., Ma, S., 2016. Thermogravimetric kinetics of lignocellulosic biomass slow pyrolysis using distributed activation energy model , Fraser - suzuki deconvolution , and iso-conversional method. Energy Convers. Manag. 118, 1-11. https://doi.org/10.1016/j.enconman.2016.03.058.

Jacob, S., Da Silva Perez, D., Dupont, C., Commandré, J.M., Broust, F., Carriau, A., Sacco, D., 2013. Short rotation forestry feedstock: influence of particle size segregation on biomass properties. Fuel 111, 820-828. https://doi.org/10.1016/j. fuel.2013.04.043.

Janković, B., Dodevski, V., Radović, I., Pijovi, M., 2019a. Physico-chemical Characterization of Carbonized Apricot Kernel Shell as Precursor for Activated Carbon Preparation in Clean Technology Utilization 236. https://doi.org/10.1016/j. jclepro.2019.117614.

Janković, B., Manić, N.G., Dodevski, V., Popović, J., Rusmirović, J.D., Tošić, M., 2019b. Characterization analysis of Poplar fluff pyrolysis products . Multi-component kinetic study. Fuel 238, 111-128. https://doi.org/10.1016/j.fuel.2018.10.064.

Janković, B., Manić, N.G., Stojiljković, D.D., Jovanović, V.V., 2020. The assessment of spontaneous ignition potential of coals using TGA-DTG technique. Combust. Flame 211, 32-43. https://doi.org/10.1016/j.combustflame.2019.09.020.

Lewandowski, I., 2016. Biomass production from lignocellulosic energy crops. In: Encyclopedia of Applied Plant Sciences. Elsevier Inc., pp. 159-163. https://doi.org/ 10.1016/B978-0-12-394807-6.00171-4

Luo, Q., Liang, D., Shen, H., 2016. Evaluation of self-heating and spontaneous combustion risk of biomass and fishmeal with thermal analysis (DSC-TG) and selfheating substances test experiments. Thermochim. Acta 635, 1-7. https://doi.org/ 10.1016/j.tca.2016.04.017.

McKendry, P., 2002. Energy production from biomass (part 1): overview of biomass. Bioresour. Technol. 83, 37-46. https://doi.org/10.1016/S0960-8524(01)00118-3.

Norman, F., Berghmans, J., Verplaetsen, F., 2013. The minimum ignition energy of coal dust in an oxygen enriched atmosphere. Chem. Eng. Trans. 31, 739-744. https://doi. org/10.3303/CET1331124.

Perejón, A., Pedro, E.S., Criado, J.M., Luis, A.P., 2011. Kinetic Analysis of Complex SolidState Reactions. A New Deconvolution Procedure 1780-1791.

Plevin Hazlehead incident [WWW Document], 2014. News feed - Plevin, 12.19.19. http $: / /$ www.plevin.co.uk/news?page $=11$.

Radojević, Balac, M., Jovanović, V.V., Stojiljković, D.D., Manić, N.G., 2018. Thermogravimetric kinetic study of solid recovered fuels pyrolysis. Hem. Ind. 72, 99-106. https://doi.org/10.2298/HEMIND171009002R. 
Rupar-Gadd, K., Forss, J., 2018. Self-heating properties of softwood samples investigated by using isothermal calorimetry. Biomass Bioenergy 111, 206-212. https://doi.org/ 10.1016/j.biombioe.2017.04.008.

Saeed, M.A., Fernandez-Anez, N., Andrews, G.E., Phylaktou, H.N., Gibbs, B.M., 2017. Steam exploded pine wood burning properties with particle size dependence. Fuel 194, 527-532. https://doi.org/10.1016/j.fuel.2017.01.028.

Saldarriaga, J.F., Aguado, R., Pablos, A., Amutio, M., Olazar, M., Bilbao, J., 2015. Fast characterization of biomass fuels by thermogravimetric analysis (TGA). Fuel 140, 744-751. https://doi.org/10.1016/j.fuel.2014.10.024.

Shankar, T.J., Wright, C.T., Boardman, R.D., Yancey, N.A., Sokhansanj, S., 2011. A review on biomass classification and composition, co-firing issues and pretreatment methods. 2011 Louisville. Kentucky. https://doi.org/10.13031/2013.37191. August 7 - August 10, 2011.

Sronsri, C., Boonchom, B., 2018. Thermal kinetic analysis of a complex process from a solid-state reaction by deconvolution procedure from a new calculation method and related thermodynamic functions of $\mathrm{Mn} 0.90 \mathrm{Co} 0.05 \mathrm{Mg} 0.05 \mathrm{HPO} \cdot 3 \mathrm{H} 2 \mathrm{O}$. Trans. Nonferrous Met. Soc. China (English Ed. 28, 1887-1902. https://doi.org/10.1016/ S1003-6326(18)64834-4.

Star Tribune, 2013. Koda Energy Invests in Safer Technology [WWW Document]. Star Trib, 12.19.19. http://www.startribune.com/biomass-burner-koda-energy-invests -in-safer-technology/216239441/.
Szamosi, Z., Tóth, P., Koós, T., Baranyai, V.Z., Szepesi, G.L., Siménfalvi, Z., 2017. Explosion characteristics of torrefied wheat straw, rape straw, and vine shoots fuels. Energy Fuels 31, 12192-12199. https://doi.org/10.1021/acs.energyfuels.7b01875.

Thrän, D., Witt, J., Schaubach, K., Kiel, J., Carbo, M., Maier, J., Ndibe, C., Koppejan, J., Alakangas, E., Majer, S., Schipfer, F., 2016. Moving torrefaction towards market introduction - technical improvements and economic-environmental assessment along the overall torrefaction supply chain through the SECTOR project. Biomass Bioenergy 89, 184-200. https://doi.org/10.1016/j.biombioe.2016.03.004.

Uemura, Y., Omar, W.N., Tsutsui, T., Yusup, S.B., 2011. Torrefaction of oil palm wastes. Fuel 90, 2585-2591. https://doi.org/10.1016/j.fuel.2011.03.021.

Uzun, H., Yıldız, Z., Goldfarb, J.L., Ceylan, S., 2017. Improved prediction of higher heating value of biomass using an artificial neural network model based on proximate analysis. Bioresour. Technol. 234, 122-130. https://doi.org/10.1016/j. biortech.2017.03.015.

Van der Stelt, M.J.C., Gerhauser, H., Kiel, J.H.A., Ptasinski, K.J., 2011. Biomass upgrading by torrefaction for the production of biofuels: a review. Biomass Bioenergy 35, 3748-3762. https://doi.org/10.1016/j.biombioe.2011.06.023.

Zborowska, M., Prądzyński, W., Kusiak, W., Stachowiak-Wencek, A., Roszyk, E., Moliński, W., 2018. A selection of the application of Pinus Sylvestris L. From Puszcza Notecka by chemical analysis. Drewno 61, 39-51. https://doi.org/10.12841/ wood.1644-3985.D10.02. 